\title{
REVISTAMATËRIA
}

\section{Influência da segregação granulométrica e do emprego de aditivos de moagem na adequação de cinzas de casca de arroz como coproduto}

\author{
Influence of the particle size segregation \\ and the additive milling use for the \\ suitability of rice husk ash as \\ byproduct
}

\author{
Daiane Calheiro ${ }^{1}$, Iara Janaína Fernandes ${ }^{1}$, \\ Amanda Gonçalves Kieling ${ }^{1}$, Carlos Alberto Mendes Moraes ${ }^{1}$, \\ Marlova Piva Kulakowski ${ }^{1}$, Feliciane Andrade Brehm ${ }^{1}$
}

\footnotetext{
${ }^{1}$ Laboratório de Caracterização e Valorização de Materiais - LCVMat - Programa de Pós Graduação em Engenharia Civil/PPGEC/Universidade do Vale do Rio dos Sinos - UNISINOS, CEP: 93022-000, São Leopoldo, RS e-mail: dcalheiro@unisinos.br; ijk.fernandes@gmail.com; amandag@unisinos.br; felicianeb@unisinos.br; cmoraes@unisinos.br; marlovak@unisinos.br
}

\section{RESUMO}

A cinza de casca de arroz (CCA) é um resíduo proveniente da combustão da casca de arroz utilizada como biomassa na produção de energia. Esta cinza é gerada em grandes quantidades e possui baixa massa específica, o que dificulta o seu gerenciamento, pois demanda muito espaço para o devido armazenamento e descarte. A CCA possui um elevado teor de sílica em sua composição, fator este que pode torná-la um material atrativo para vários segmentos industriais. Neste contexto, este trabalho tem como objetivo avaliar a influência do beneficiamento físico da cinza de casca de arroz, por meio de processos de segregação granulométrica e moagem, com e sem o uso de aditivos, nas características deste material e na sua adequação como coproduto. A metodologia experimental utilizada para o desenvolvimento deste trabalho envolveu a segregação e moagem da CCA (com e sem aditivos de moagem), caracterização química, física e estrutural das amostras de CCA bruta, segregadas e moídas. Os resultados obtidos indicam que a segregação granulométrica se apresenta como fator determinante para a utilização da CCA como coproduto. Com relação à moagem, pode-se verificar que o diâmetro médio das partículas diminui e a massa específica das amostras aumenta, com o aumento do tempo de moagem. Entretanto, verifica-se que os aditivos usados neste trabalho, nas concentrações testadas, não influenciam significativamente na redução do diâmetro das partículas.

Palavras-chave: cinza de casca de arroz, beneficiamento, segregação, moagem, caracterização.

\begin{abstract}
The rice husk ash (RHA) is a residue from the rice husk combustion used as biomass in energy production. This ash is generated in large amount and due to its low density it makes complicate its management, in addition it demands a lot of space for proper storage and disposal. The RHA has high silica content in its composition, a factor that may turn it in an attractive material for several industries. In this context, this work aims to evaluate the influence of physical processing of rice husk ash through the sieve segregation processes and grinding with and without the additives use, the characteristics of this material and its suitability as a coproduct. The experimental methodology used to develop this work involved the segregation and grinding of the RHA (with and without grinding additives), chemical, physical and structural characterization of samples raw-based RHA, segregated and ground. The results indicate that the particle size segregation presents as a determinant factor for the use of RHA as coproduct. With regard to the grinding, it can be seen that the average diameter of the particles decreases and the density of the samples increases with increasing milling time. However, it appears that the used additives did not significantly influence the reduction of particle diameter in the concentrations tested.
\end{abstract}

Keywords: rice husk ash, treatment, segregation, ground, characterization. 


\section{INTRODUÇÃO}

Muitas empresas beneficiadoras de arroz utilizam a casca de arroz como combustível para geração de energia e/ou vapor. Essas empresas são geralmente de pequeno porte e não possuem processos para o aproveitamento ou descarte adequado das cinzas geradas no processo de combustão. A cinza de casca de arroz (CCA), devido à sua baixa massa específica, necessita de uma grande área de armazenamento para posterior descarte. Dessa forma, estas cinzas muitas vezes são depositadas em terrenos baldios ou lançadas em rios e córregos, provocando a contaminação de solo e água, além do risco à saúde da população, por contaminar o ar e poder causar silicose, em função do elevado teor de sílica e baixas dimensões de partículas.

O Brasil é o nono maior produtor de arroz, sendo o maior fora da Ásia. O país colheu em 2012, de acordo com as estatísticas da Organização das Nações Unidas para Alimentação e Agricultura FAO, quase 11,5 milhões de toneladas de arroz em casca [1]. A safra de 2013-2014, segundo FAO Rice Market Monitor [2], foram de 12,8 milhões de toneladas. Considerando que as cascas representam $20 \%$ desse valor [3], a produção anual desse resíduo tem sido da ordem de aproximadamente 2,3 milhões de toneladas. Quando esta casca é utilizada como combustível, 20\% é convertido em cinza [4], podendo gerar assim quase 500 mil toneladas de CCA ao ano.

A CCA geralmente apresenta em sua composição: dióxido de silício ou comumente denominada sílica $\left(\mathrm{SiO}_{2}\right)$, carbono $(\mathrm{C})$, óxido de potássio $\left(\mathrm{K}_{2} \mathrm{O}\right)$, óxido fosfórico $\left(\mathrm{P}_{2} \mathrm{O}_{5}\right)$, óxido de cálcio $(\mathrm{CaO})$ e em menores quantidades compostos de magnésio $(\mathrm{Mg})$, Ferro $(\mathrm{Fe})$ e Sódio (Na) [5]. A combustão da casca de arroz origina cinzas com alto teor de sílica, com formas estruturais variáveis (amorfa e/ou cristalina). A maior ou menor quantidade de sílica e a sua forma estrutural depende, entre outros fatores, do tipo de equipamento que realiza a combustão da casca de arroz, do tempo de permanência nos fornos e da temperatura de combustão, bem como da velocidade de resfriamento das cinzas [6]. Cordeiro [7] observa, que entre a maioria dos autores existe concordância com relação à produção de CCA amorfas em temperaturas próximas a $700^{\circ} \mathrm{C}$. Acima deste valor é possível perceber a formação de pontos cristalinos.

Normalmente, para produção controlada de CCA, de forma a garantir que todo processo ocorra a uma mesma temperatura, a combustão é realizada por meio de sistemas de leito fluidizado [8, 9]. A combustão realizada nestes tipos de reatores, em geral, apresenta vantagem para a produção de CCA amorfa quando comparada à combustão em grelha, devido às características como inexistência de gradientes de temperatura ou regiões estagnadas. No entanto, em função dos custos de implantação de processos de combustão por leito fluidizado, a maioria das empresas, que utilizam a casca de arroz como biomassa para geração de energia e/ou vapor no Brasil, adotam sistemas de combustão em grelha, onde não ocorre a combustão de forma homogênea [10]. A combustão neste processo compreende a deposição da biomassa em um sistema de grelha, onde ocorrem os processos de secagem, de volatilização e combustão. Porém, apesar de menores custos de implantação, o sistema de combustão em grelha apresenta desvantagens de utilização, principalmente relacionadas à baixa eficiência, elevadas emissões de poluentes atmosféricos, além de problemas comuns nos reatores, como deposição e corrosão. Tudo isso faz com que, usualmente, cinzas geradas neste tipo de sistema apresentem maior variação de qualidade, maiores teores de carbono e, sílica parcialmente cristalina [10, 11].

De um modo geral, os resultados obtidos nas pesquisas brasileiras concluem que a CCA possui boa atividade pozolânica [11]. Além de ser uma boa alternativa como material pozolânico para a construção civil, a CCA também pode ser utilizada em outros segmentos industriais. Entre as principais aplicações destacamse: fabricação de vidros e materiais refratários, produção de carbeto de silício, silicatos e sílica pura, uso como adsorvente e utilização como agente de reforço para produção de polímeros [3]. No entanto, para a grande maioria destas aplicações, são necessários diferentes processos de beneficiamento, como segregação granulométrica e moagem.

A segregação granulométrica prévia pode ser necessária com o propósito de melhorar o aproveitamento da CCA, removendo impurezas, principalmente cascas de arroz não queimadas ou queimadas de forma incompleta e CCA com estrutura cristalina (em função de pré-fusão de uma pequena quantidade de casca, como foi mencionado anteriormente, em especial nos processos baseados em grelhas deslizantes).

Já a moagem tem sido um dos tratamentos físicos mais empregados, influenciando nas características da CCA. A moagem é realizada com o objetivo de reduzir o tamanho das partículas das cinzas e aumentar sua área superficial. É uma operação capaz de modificar propriedades físicas da cinza como a superfície específica e granulometria, o que influencia fortemente na sua reatividade [7, 12]. A moagem é uma das mais importantes operações na indústria mineral, e se caracteriza por alto consumo de energia elétrica [13].

Neste sentido, a utilização de aditivos de moagem visa reduzir o tempo e melhorar a qualidade dos materiais moídos em relação à homogeneidade do tamanho, e área superficial do grão. Com esses aditivos é 
possível também reduzir a aglomeração dos materiais dentro do moinho, e evitar a aderência das partículas finas nos corpos moedores. O uso de aditivos favorece a moagem pela redução das forças de adesão entre as partículas, por evitar a formação de agregações e aderências do material ao meio moedor [14]. No entanto, os aditivos de moagem comerciais normalmente possuem um alto custo e são, muitas vezes, compostos de substâncias orgânicas e voláteis que podem acarretar risco à saúde humana e contaminação do ar. Assim, também é importante estudar a possibilidade de utilização de resíduos industriais como aditivos de moagem.

Neste contexto, este trabalho teve como objetivo avaliar a influência do beneficiamento físico de uma cinza de casca de arroz, obtida em um sistema de combustão tipo grelha, com relação aos processos de segregação granulométrica e moagem com e sem o uso de aditivos, nas características deste material e na sua adequação como coproduto.

\section{MATERIAIS E MÉTODOS}

A CCA utilizada neste trabalho é oriunda do processo de combustão em leito fixo por grelha de uma empresa da Grande Porto Alegre. Neste sistema contínuo, a casca de arroz é alimentada automaticamente, modulada de acordo com a pressão de vapor da caldeira. O material atravessa a fornalha, com temperatura que varia entre $600^{\circ} \mathrm{C}$ e $700^{\circ} \mathrm{C}$, por meio de uma grelha deslizante, durante 9 minutos.

A metodologia desenvolvida neste trabalho apresenta três etapas:

1. Segregação da CCA bruta;

2. Moagem com e sem o uso de aditivos;

3. Caracterização físico-química das amostras CCA bruta, segregada e moída com e sem aditivo.

\subsection{Segregação Granulométrica da CCA}

Para a segregação foi utilizada a metodologia desenvolvida por Kieling [11]. Foi realizada por meio de agitador de peneiras, utilizando na continuidade dos experimentos, somente a fração passante na peneira 1,2mm.

Esta segregação foi necessária, pois segundo estudos realizados por Kieling [11], observa-se que na fração retida na peneira de abertura de 1,2 mm corresponde a impurezas como: cascas de arroz não ou parcialmente combustas, cascas fundidas entre outras impurezas oriundas do processo de combustão por grelha.

\subsection{Moagem da CCA}

Após a segregação, a CCA foi seca em estufa a $105^{\circ} \mathrm{C}( \pm 5)$ e moída a seco com e sem o uso dos aditivos nos tempos de moagem de 30 minutos, 1, 2 e 4 horas em moinho de bolas de porcelana, com capacidade de 7,5L acionado por gira moinho horizontal de dois andares, modelo CT - 240, marca Servitech. O moinho foi carregado com $5 \mathrm{~kg}$ de esferas de alumina e $1 \mathrm{~kg}$ de cinza a uma velocidade de 54rpm. Foram utilizados 2 aditivos. Um aditivo comercial que é usado na moagem do cimento, e como segundo foi testado um resíduo sólido industrial. O aditivo comercial de moagem foi o da marca SikaGrind-200, composto de um derivado de amina livre de cloretos. É um aditivo líquido que facilita a moagem, e foi desenvolvido especificamente para obter cimentos com ganhos na resistência inicial. Este ajuda a neutralização das cargas elétricas na superfície das partículas e facilita a separação das partículas [20]. Utilizou-se quantidade entre a mínima e a máxima recomendada pelo fabricante, sendo as amostras moídas com adição de 0,03\%, 0,045\% e 0,06\% em relação à massa de CCA. Dentre vários resíduos industriais avaliados, o escolhido é o Pó de granalha, de origem metalúrgica, do setor de fundição. O Pó de granalha (PG) é um resíduo oriundo do processo de acabamento por jato de granalha de peças de ferro fundido. O PG foi adicionado nas proporções de $2 \%$, 6\% e $10 \%$ de resíduo sobre a massa de amostras.

\subsection{Caracterização Físico-Química das CCAs}

Para análise da composição química foi utilizada a técnica de Fluorescência de Raios-X (FRX), usando Espectrômetro de Fluorescência de Raios-X por Energia dispersiva, EDX 720 HS, marca Shimadzu. Além da análise das CCAs, também foi realizada análise para verificar a composição do resíduo PG, utilizado como aditivo de moagem. A análise de perda ao fogo (PF) foi efetuada de acordo com a norma CEMP $n^{\circ} 120$ [15].

Para identificação da composição mineralógica do material, foi realizada análise de Difração de Raios-X (DRX), em Difratômetro Siemens D5000. A identificação dos picos obtidos no difratograma foi realizada utilizando o Software Philips Analytical e sua respectiva base de dados.

Foram realizadas análises de Microscopia Eletrônica de Varredura (MEV), nas amostras com aditivos, 
para verificar a evolução da moagem dos grãos, presença de contaminantes e o comportamento dos aditivos moídos com a CCA. As imagens foram obtidas pelo microscópio eletrônico de varredura, marca Shimadzu SSX-550.

A massa específica das amostras foi determinada conforme NBR NM 23 [16]. Este método determina a massa específica por meio do frasco volumétrico de Le Chatelier.

A distribuição granulométrica das partículas foi determinada pelo método de granulometria por difração a laser, empregando-se o analisador de distribuição de tamanho de partículas CILAS 1064 Liquid. Para as amostras bruta e segregada foi determinada a granulometria de acordo com a Norma CEMP 081 - Determinação da distribuição granulométrica e módulo de finura [17]. Para aumentar a confiabilidade dos ensaios, estes foram analisados em triplicatas.

Para facilitar a identificação das amostras, a Tabela 1 apresenta as nomenclaturas das amostras utilizadas neste trabalho.

Tabela 1: Identificação das Amostras.

\begin{tabular}{l|l}
\hline AMOSTRA & IDENTIFICAÇÃo \\
\hline CCA Bruta & Cinza de Casca de Arroz sem nenhum tipo de tratamento \\
\hline CCA Segregada & Cinza de Casca de Arroz passante na peneira 1,2mm \\
\hline CCA Moída & Cinza de Casca de Arroz segregada e moída sem aditivo \\
\hline CCA Ad. Com. 0,03\% & Cinza de Casca de Arroz segregada e moída com 0,03\% de aditivo comercial \\
\hline CCA Ad. Com. 0,045\% & Cinza de Casca de Arroz segregada e moída com 0,045\% de aditivo comercial \\
\hline CCA Ad. Com. 0,06\% & Cinza de Casca de Arroz segregada e moída com 0,06\% de aditivo comercial \\
\hline CCA Ad. PG 2\% & Cinza de Casca de Arroz segregada e moída com $2 \%$ do resíduo pó de granalha \\
\hline CCA Ad. PG 6\% & Cinza de Casca de Arroz segregada e moída com $6 \%$ do resíduo pó de granalha \\
\hline CCA Ad. PG $10 \%$ & Cinza de Casca de Arroz segregada e moída com 10\% do resíduo pó de granalha \\
\hline
\end{tabular}

\section{RESULTADOS E DISCUSSÃo}

\subsection{Segregação Granulométrica da CCA}

Na segregação granulométrica observou-se, pela análise visual (Figura 1), que o material retido na peneira 1,2 mm é constituído principalmente de CCA na fase cristalina (cor branca), casca não queimada e outras impurezas oriundas do processo de combustão. Já o material passante apresentou-se como uma amostra mais homogênea. O material não passante na peneira 1,2 mm representou em torno de 8\% em massa.

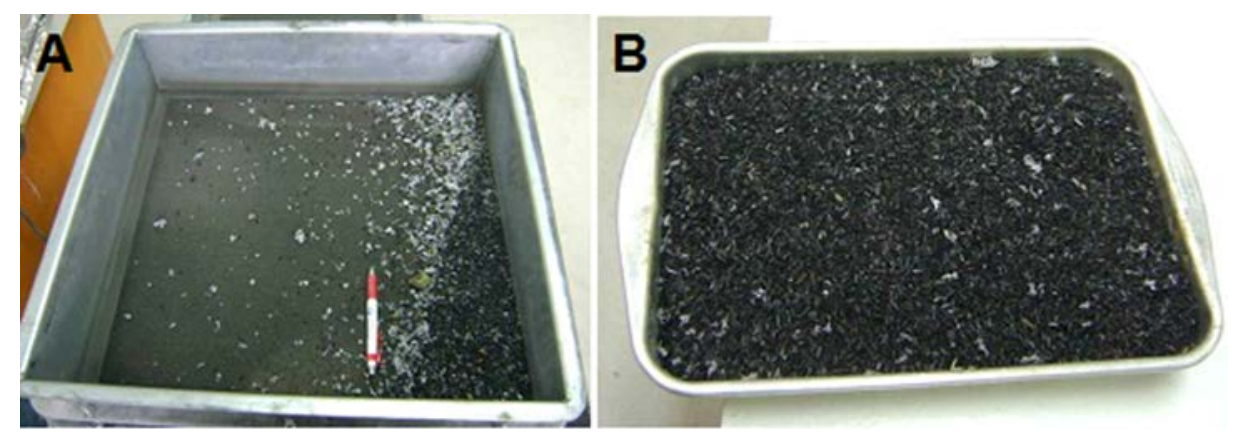

Figura 1: A - CCA retida na peneira 1,2mm; B - CCA passante na peneira 1,2mm.

As distribuições granulométricas da CCA bruta e da CCA segregada estão apresentadas na Figura 2, onde se observa que a etapa de segregação por retirar uma fração grosseira não altera a distribuição de partículas heterogêneas da CCA.

Dessa forma, devido à remoção de impurezas como cascas não queimadas, materiais cristalinos e metálicos, pode-se verificar que a etapa de segregação granulométrica é de suma importância a sua adequação para a maioria das aplicações. 


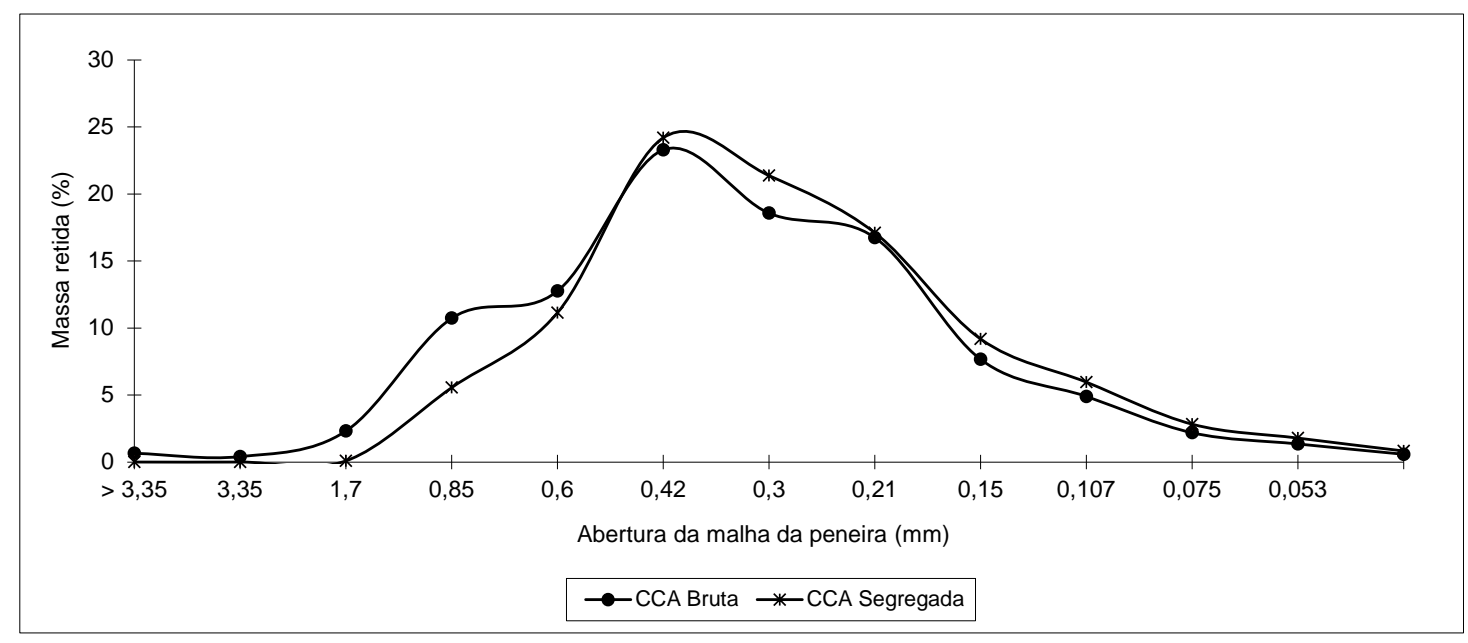

Figura 2: Distribuição Granulométrica da CCA Bruta e Segregada.

\subsection{Análise Química e Perda ao Fogo}

Os resultados da caracterização química e de perda ao fogo das CCAs, sem e com aditivos, estão apresentados na Tabela 2.

Tabela 2: Composição química das CCAs (\% em massa).

\begin{tabular}{l|l|l|l|l|l|l|l|l|l|l|l}
\hline AMOSTRA & $\mathrm{SiO}_{2}$ & $\mathbf{Z n O}$ & $\mathrm{Fe}_{2} \mathrm{O}_{3}$ & $\mathbf{M n O}$ & $\mathrm{TiO}_{2}$ & $\mathbf{C a O}$ & $\mathbf{K}_{2} \mathrm{O}$ & $\mathrm{SO}_{3}$ & $\mathbf{P}_{2} \mathrm{O}_{5}$ & $\mathrm{Al}_{2} \mathrm{O}_{3}$ & $\mathbf{P F}$ \\
\hline CCA Bruta & 76,395 & $\mathrm{ND}$ & $\mathrm{ND}$ & 0,039 & $\mathrm{ND}$ & 0,046 & 0,602 & 0,001 & 0,115 & $\mathrm{ND}$ & 7,938 \\
\hline CCA Segregada e Moída & 80,361 & 0,001 & 0,001 & 0,037 & $\mathrm{ND}$ & 0,088 & 0,652 & 0,049 & 0,111 & $\mathrm{ND}$ & 6,660 \\
\hline & & & & & & & & & & & \\
CCA Ad. Com. 0,03\% & 83,515 & 0,001 & $\mathrm{ND}$ & 0,036 & $\mathrm{ND}$ & 0,083 & 0,668 & 0,030 & 0,101 & $\mathrm{ND}$ & 6,360 \\
\hline & & & & & & & & & & & \\
CCA Ad. Com. 0,045\% & 82,354 & 0,001 & $\mathrm{ND}$ & 0,036 & $\mathrm{ND}$ & 0,086 & 0,660 & 0,047 & 0,102 & $\mathrm{ND}$ & 6,330 \\
\hline & & & & & & & & & & & \\
CCA Ad. Com. 0,06\% & 82,671 & 0,001 & $\mathrm{ND}$ & 0,037 & $\mathrm{ND}$ & 0,074 & 0,658 & 0,038 & 0,111 & $\mathrm{ND}$ & 6,760 \\
\hline CCA Ad. PG 2\% & 83,488 & 0,001 & 0,284 & 0,035 & $\mathrm{ND}$ & 0,083 & 0,658 & 0,043 & 0,113 & $\mathrm{ND}$ & 6,200 \\
\hline CCA Ad. PG 6\% & 80,426 & 0,001 & 0,893 & 0,030 & $\mathrm{ND}$ & 0,084 & 0,636 & 0,049 & 0,104 & $\mathrm{ND}$ & 6,330 \\
\hline CCA Ad. PG 10\% & 78,581 & 0,002 & 1,307 & 0,030 & 0,001 & 0,070 & 0,604 & 0,046 & 0,118 & $\mathrm{ND}$ & 5,440 \\
\hline
\end{tabular}

PF = Perda ao Fogo; ND = Não Detectado; Cl, Na e Mg não foram detectados em nenhuma amostra.

Comparando os resultados da Tabela 2, nota-se que a adição dos aditivos na CCA não alterou significativamente sua composição. Porém, as amostras CCA Ad. PG apresentaram o elemento ferro na sua composição química, o que era esperado devido à composição química do resíduo PG (Tabela 3) conter este elemento. Está análise química foi realizada com o intuito de verificar a composição química da CCA com a presença de aditivos.

Também se observa uma variação no teor de sílica, quando se compara a CCA bruta com a CCA moída e segregada. Esta variação pode ser devido à presença de impurezas do processo de combustão na CCA Bruta. Como estas impurezas foram removidas pela segregação, aumentou o percentual de sílica e reduziu o percentual de perda ao fogo.

Com relação à presença de ferro na composição química de CCA, Tashima [18] estudou uma cinza com um teor de $0,86 \%$ de Fe. O autor produziu uma CCA e avaliou seu comportamento em matrizes de cimento Portland com o intuito de avaliar a atividade pozolânica da cinza. Os resultados mostraram que a CCA apresentou características adequadas para a utilização como material pozolânico em matrizes de cimento Portland e, a princípio, o autor não verificou nenhuma possível influência negativa da presença de ferro neste produto. Ainda avaliando o teor de ferro, estudo desenvolvido por Costa et al. [21] que avaliou a CCA em borracha natural constatou que alguns óxidos, entre eles o de ferro, quando usados em combinação com o de 
zinco apresentaram um efeito positivo sobre a vulcanização.

Analisando o teor de sílica das CCA com a PF, percebe-se que quanto maior o teor de sílica menor é a perda ao fogo. Este resultado está de acordo com outros autores como Pouey [12] e Kieling [11], que constataram que o aumento do teor de sílica está relacionado principalmente com o valor de PF, que é menor em amostras com percentuais elevados de sílica.

A análise química do resíduo PG está apresentada na Tabela 3.

Tabela 3: Composição química semiquantitativa do Resíduo PG (\% em massa) via EDS/MEV.

\begin{tabular}{l|l|l|l|l|l|l|l|l|l|l|l}
\hline & Si & Cr & Fe & Mn & K & Ti & Zn & S & Cu & Zr & PF \\
\hline Resíduo PG & 86,000 & 0,018 & 12,231 & 0,236 & 0,001 & ND & 0,014 & 0,08 & 0,010 & 0,002 & ND \\
\hline
\end{tabular}

Quando comparadas as composições químicas do resíduo PG com a CCA utilizada neste trabalho, verificou-se que o resíduo é semelhante à cinza com exceção de alguns elementos que estão presentes em baixa concentração $(\mathrm{Cr}$ e $\mathrm{Cu})$.

Analisando o teor de ferro do resíduo PG com os teores deste mesmo elemento nas CCA com Ad. PG, percebe-se que os valores são proporcionais, ou seja, conforme aumenta a concentração do resíduo aumenta o teor de ferro em $2,32 \%, 7,30 \%$ e $10,64 \%$, respectivamente, quando comparado aos $12 \%$ de ferro encontrado no resíduo PG.

\subsection{Difração de Raios X}

As fases cristalinas presentes nas amostras analisadas, determinadas por difração de raios $\mathrm{X}$, estão descritas na Tabela 4 e os difratogramas podem ser observados nas figuras 3, 4, 5 e 6. Os difratogramas das CCAs com aditivo comercial não tiveram variação, já os com o resíduo PG, a partir de 6\%, mostram a presença de quartzo.

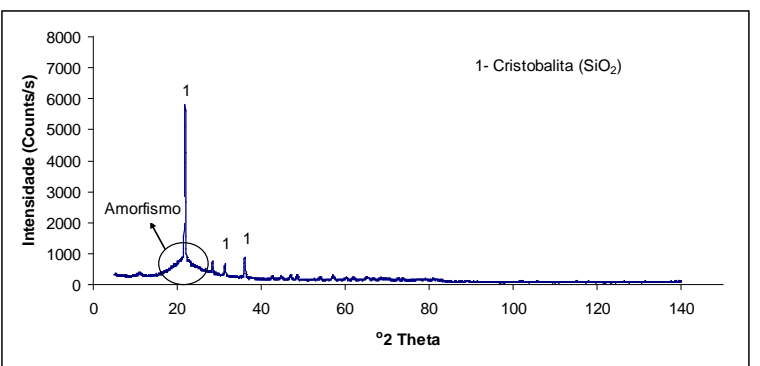

Figura 3: Difratograma da CCA Bruta.

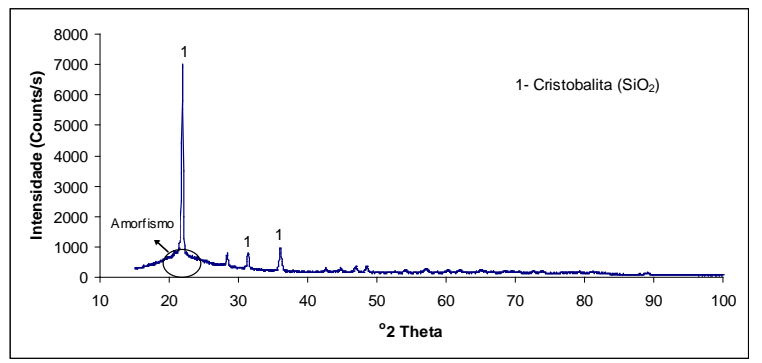

Figura 5: Difratograma da CCA Ad. Com. 0,03\%.

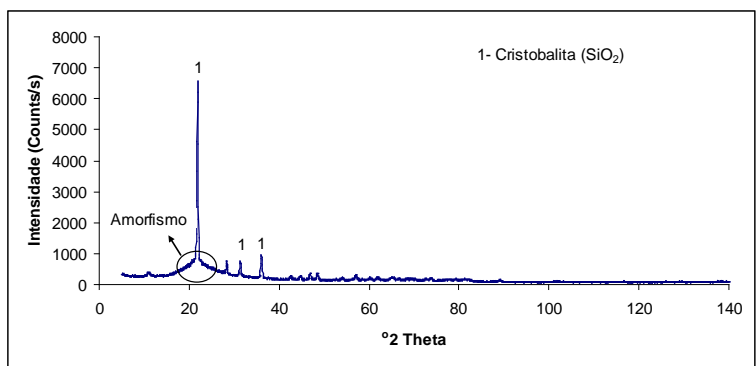

Figura 4: Difratograma da CCA Segregada e moída.

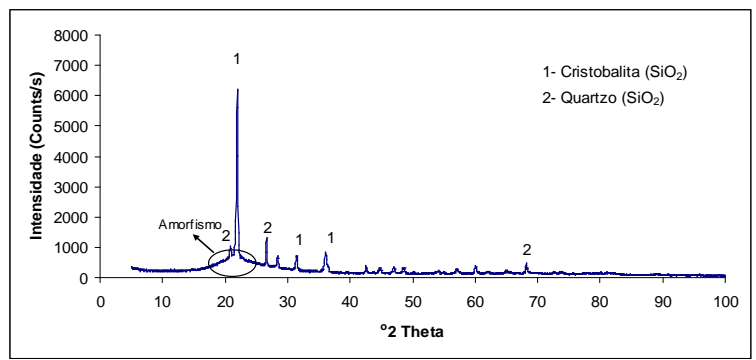

Figura 6: Difratograma da CCA Ad. PG 10\%. 
Tabela 4: Fases encontradas nas amostras.

\begin{tabular}{l|l|l}
\hline AMOSTRA & MINERAL & FORMULA \\
\hline CCA Bruta & Cristobalita & $\mathrm{SiO}_{2}$ \\
\hline CCA Segregada e moída & Cristobalita & $\mathrm{SiO}_{2}$ \\
\hline CCA Ad. Com. 0,03\% & Cristobalita & $\mathrm{SiO}_{2}$ \\
\hline CCA Ad. Com. 0,045\% & Cristobalita & $\mathrm{SiO}_{2}$ \\
\hline CCA Ad. Com. 0,06\% & Cristobalita & $\mathrm{SiO}_{2}$ \\
\hline CCA Ad. PG 2\% & Cristobalita & $\mathrm{SiO}_{2}$ \\
\hline CCA Ad. PG 6\% & Cristobalita; Quartzo & $\mathrm{SiO}_{2} ; \mathrm{SiO}_{2}$ \\
\hline CCA Ad. PG 10\% & Cristobalita; Quartzo & $\mathrm{SiO}_{2} ; \mathrm{SiO}_{2}$ \\
\hline
\end{tabular}

Foi identificada a presença de cristobalita $\left(\mathrm{SiO}_{2}\right)$ em todas as amostras de cinza de casca de arroz. O sistema de combustão que deu origem à CCA utilizada nesta pesquisa é o de grelha deslizante, e mesmo a temperatura de combustão sendo controlada entre $600^{\circ} \mathrm{C}$ e $700^{\circ} \mathrm{C}$ pode ocorrer a formação de material cristalino. Isto pode ser devido ao deslizamento da CCA na grelha, que faz com que as cinzas mais próximas da chama atinjam uma temperatura mais elevada, gerando assim uma variação de temperatura durante a combustão entre a superfície superior (em contato com a chama) e inferior, ocasionando fases cristalinas. Cordeiro [7] salienta, que existe concordância da literatura com relação à produção de CCA amorfas em temperaturas próximas a $700^{\circ} \mathrm{C}$. Acima deste valor é possível perceber a formação de pontos cristalinos. Fica claro na comparação com vários trabalhos de caracterização $[7,11,12$, 18] de cinzas de casca de arroz originadas em processo de combustão por grelha, a presença do halo de amorfismo entre os ângulos 15 e 30 graus, evidenciando que grande parte da amostra está no estado amorfo. Esta afirmação é corroborada pelos testes de pozolanicidade desenvolvidos por Kieling [11] realizada em uma CCA da mesma origem.

Devido a esta estrutura, a CCA pode ser aplicada em diversas áreas. Fernandes [22] estudou CCAs de diferentes origens para aplicação em compósitos poliméricos e concluiu que, com relação à caracterização destas quando comparadas com sílicas comerciais, várias das propriedades analisadas foram semelhantes e, dessa forma, indicaram a existência de viabilidade de substituição da sílica comercial por CCA para diversos tipos de materiais poliméricos.

Em relação às amostras de CCA, que foram moídas com auxílio de aditivo comercial, não houve alteração na sua composição mineralógica, assim como na CCA que recebeu $2 \%$ do aditivo pó de granalha. No entanto, nas CCA com $6 \%$ e $10 \%$ de aditivo pó de granalha foram identificados picos de quartzo, devido à origem do aditivo (fundição em moldes de areia).

\subsection{Microscopia Eletrônica de Varredura}

A Figura 3 apresenta a morfologia observada para as amostras CCA Moída (A), CCA Ad. PG (B) e CCA Ad. Com. (C).
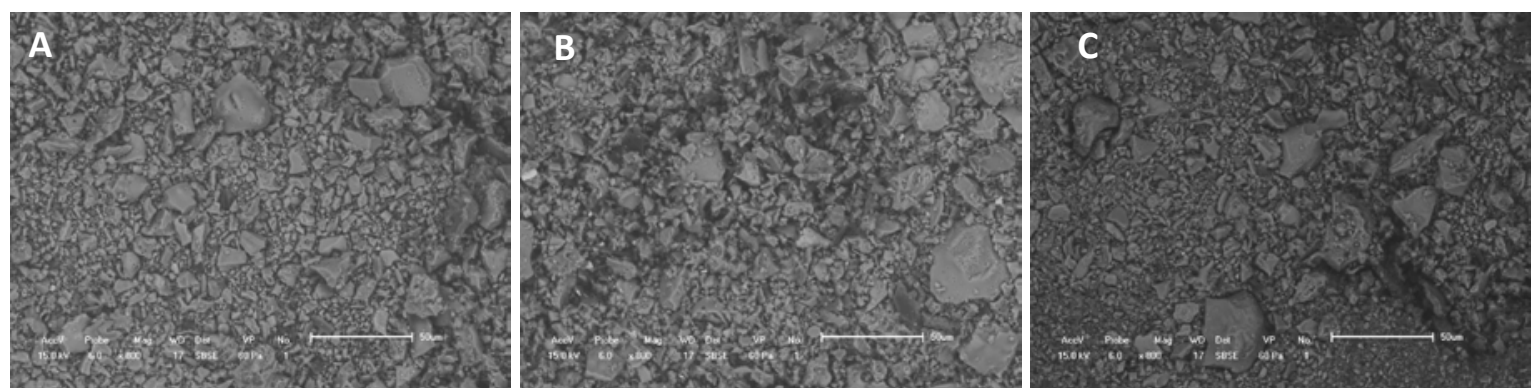

Figura 3: A - Micrografia CCA Moída (aumento original de 800x); B - Micrografia CCA Ad. PG10\% (aumento original de 800x); C - Micrografia CCA Ad. Com., 0,06\% (aumento original de 800x).

Analisando as micrografias das CCAs, percebe-se que a CCA Moída e a CCA Ad. Com. não apresen- 
taram diferenças visuais em sua microestrutura. Mas, quando comparadas com a CCA Ad. PG, observa-se a presença de partículas heterogêneas (pontos brancos), que devem ser materiais provavelmente metálicos ou magnetita $\left(\mathrm{Fe}_{3} \mathrm{O}_{4}\right)$, decorrentes da composição do aditivo PG. Para uma melhor comparação entre as amostras, foi realizada uma espectrometria por dispersão de energia (EDS) de toda a região existente nas micrografias das CCA (Tabela 5), que permite avaliar a composição química, de caráter indicativo, das amostras moídas.

Tabela 5: EDS para CCA Moída, CCA Ad. Com. e CCA Ad. PG.

\begin{tabular}{|c|c|c|c|}
\hline ELEMENTO & $\begin{array}{l}\text { \% (MASSA) } \\
\text { CCA MOÍDA }\end{array}$ & $\begin{array}{c}\% \text { (MASSA) } \\
\text { CCA AD. COM. } 0,06 \%\end{array}$ & $\begin{array}{c}\% \text { (MASSA) CCA AD. } \\
\text { PG 10\% }\end{array}$ \\
\hline $\mathrm{C}$ & 11,156 & 16,509 & 10,708 \\
\hline $\mathrm{O}$ & 62,850 & 61,754 & 56,537 \\
\hline $\mathrm{Na}$ & ND & 0,201 & 0,242 \\
\hline $\mathrm{Mg}$ & 0,252 & 0,231 & 0,299 \\
\hline $\mathrm{Al}$ & 0,385 & 0,333 & 0,464 \\
\hline Si & 23,699 & 19,777 & 29,048 \\
\hline $\mathrm{P}$ & 0,229 & 0,184 & ND \\
\hline K & 1,097 & 0,880 & 1,373 \\
\hline $\mathrm{Ca}$ & 0,332 & 0,131 & 0,444 \\
\hline $\mathrm{Fe}$ & ND & ND & 0,885 \\
\hline TOTAL & 100 & 100 & 100 \\
\hline
\end{tabular}

Comparando os resultados de EDS, pode-se verificar que a CCA segregada e moída e CCA Ad. Com. são muito semelhantes em sua composição química. Em relação à CCA Ad. PG, a composição química também não varia muito ,quando comparada com a CCA segregada e moída, com exceção do Fe. A presença de ferro na CCA Ad. PG era esperada, pois este resíduo é oriundo do processo de jateamento de granalha das peças de ferro fundido, assim como um maior percentual de Si em função da sua presença no PG.

\subsection{Massa Específica}

Os valores de massa específica para as amostras de CCA, sem e com aditivos, estão apresentados na Tabela 6.

Tabela 6: Resultados de massa específica da CCA em g/ $\mathrm{cm}^{3}$.

\begin{tabular}{|c|c|c|}
\hline AMOSTRA & TEMPO DE MOAGEM & MASSA ESPECÍFICA $\left(\mathrm{g} / \mathrm{cm}^{3}\right)$ \\
\hline CCA Bruta & - & 1,98 \\
\hline CCA Segregada & - & 2,10 \\
\hline \multirow{4}{*}{ CCA Moída } & 30min & 2,10 \\
\hline & $1 \mathrm{~h}$ & 2,08 \\
\hline & $2 \mathrm{~h}$ & 2,11 \\
\hline & $4 \mathrm{~h}$ & 2,12 \\
\hline \multirow{4}{*}{ CCA Ad. Com 0,03\% } & 30min & 2,05 \\
\hline & $1 \mathrm{~h}$ & 2,09 \\
\hline & $2 \mathrm{~h}$ & 2,10 \\
\hline & $4 \mathrm{~h}$ & 2,10 \\
\hline \multirow{4}{*}{ CCA Ad. Com 0,045\% } & 30min & 2,04 \\
\hline & $1 \mathrm{~h}$ & 2,07 \\
\hline & $2 \mathrm{~h}$ & 2,12 \\
\hline & $4 \mathrm{~h}$ & 2,11 \\
\hline CCA Ad. Com 0,06\% & 30min & 2,08 \\
\hline
\end{tabular}




\begin{tabular}{l|l|l}
\hline \multirow{2}{*}{ AMOSTRA } & TEMPO DE MOAGEM & MASSA ESPECÍFICA $\mathbf{( g / \mathbf { c m } ^ { 3 } )}$ \\
\hline & $1 \mathrm{~h}$ & 2,08 \\
\cline { 2 - 3 } & $2 \mathrm{~h}$ & 2,07 \\
\cline { 2 - 3 } & $4 \mathrm{~h}$ & 2,13 \\
\hline \multirow{5}{*}{ CCA Ad. PG 2\% } & $30 \mathrm{~min}$ & 2,06 \\
\cline { 2 - 3 } & $1 \mathrm{~h}$ & 2,08 \\
\cline { 2 - 3 } & $2 \mathrm{~h}$ & 2,11 \\
\cline { 2 - 3 } & $4 \mathrm{~h}$ & 2,11 \\
\hline \multirow{5}{*}{ CCA Ad. PG 6\% } & $30 \mathrm{~min}$ & 2,08 \\
\cline { 2 - 3 } & $1 \mathrm{~h}$ & 2,10 \\
\cline { 2 - 3 } & $2 \mathrm{~h}$ & 2,10 \\
\cline { 2 - 3 } & $4 \mathrm{~h}$ & 2,14 \\
\hline \multirow{5}{*}{ CCA Ad. PG 10\% } & $30 \mathrm{~min}$ & 2,11 \\
\cline { 2 - 3 } & $1 \mathrm{~h}$ & 2,14 \\
\cline { 2 - 3 } & $2 \mathrm{~h}$ & 2,14 \\
\hline & $4 \mathrm{~h}$ & 2,17 \\
\hline
\end{tabular}

Pode-se inferir que a massa específica das amostras aumenta com o tempo de moagem. Ao analisar a massa específica em relação à adição dos aditivos e às concentrações, foi observado que a maior variação comparada com a CCA moída é a CCA Ad. PG $10 \%$, que foi de 0,5\%, 2,9\%, 1,4\% e 2,4\% para os tempos de moagem de 30 min, $1 \mathrm{~h}, 2 \mathrm{~h}$ e $4 \mathrm{~h}$, respectivamente. Isto pode ser devido à composição do resíduo PG, e de sua massa específica que é de $2,87 \mathrm{~g} / \mathrm{cm}^{3}$.

\subsection{Distribuição Granulométrica}

Na Tabela 7 são apresentadas as distribuições granulométricas das CCA sem e com aditivo.

Tabela 7: Distribuição granulométrica das partículas.

\begin{tabular}{|c|c|c|c|c|c|}
\hline AMOSTRA & TEMPO DE MOAGEM & $\mathrm{D} 10(\mathrm{~m} \mu)$ & D50 $(\mathrm{m} \mu)$ & $\mathrm{D} 90(\mathrm{~m} \mu)$ & D. MÉDIO $(m \mu)$ \\
\hline \multirow{4}{*}{ CCA Moída } & $30 \mathrm{~min}$ & 9,03 & 40,27 & 80,02 & 43,07 \\
\hline & $1 \mathrm{~h}$ & 5,08 & 27,3 & 56,68 & 29,48 \\
\hline & $2 \mathrm{~h}$ & 2,15 & 10,69 & 25,46 & 12,7 \\
\hline & $4 \mathrm{~h}$ & 1,53 & 7,78 & 19,38 & 9,38 \\
\hline \multirow{4}{*}{ CCA Ad. Com 0,03\% } & $30 \mathrm{~min}$ & 10,24 & 42,97 & 84,62 & 45,82 \\
\hline & $1 \mathrm{~h}$ & 5,79 & 29,39 & 60,41 & 31,77 \\
\hline & $2 \mathrm{~h}$ & 2,46 & 12,64 & 33,42 & 15,72 \\
\hline & $4 \mathrm{~h}$ & 1,6 & 7,79 & 20,02 & 9,48 \\
\hline \multirow{4}{*}{ CCA Ad. Com 0,045\% } & 30min & 10,01 & 43,07 & 85,14 & 45,98 \\
\hline & $1 \mathrm{~h}$ & 4,87 & 25,56 & 53,69 & 27,78 \\
\hline & $2 \mathrm{~h}$ & 2,29 & 11,38 & 30,07 & 14,22 \\
\hline & $4 \mathrm{~h}$ & 1,67 & 7,74 & 19,2 & 9,33 \\
\hline \multirow{4}{*}{ CCA Ad. Com 0,06\% } & $30 \mathrm{~min}$ & 11,08 & 43,69 & 92,57 & 48,59 \\
\hline & $1 \mathrm{~h}$ & 5,14 & 25,42 & 52,97 & 27,63 \\
\hline & $2 \mathrm{~h}$ & 2,69 & 13,47 & 35,64 & 16,76 \\
\hline & $4 \mathrm{~h}$ & 1,66 & 8,01 & 19,89 & 9,67 \\
\hline CCA Ad. PG 2\% & 30min & 9,27 & 40,17 & 80,28 & 43,17 \\
\hline
\end{tabular}




\begin{tabular}{|c|c|c|c|c|c|}
\hline AMOSTRA & TEMPO DE MOAGEM & $\mathrm{D} 10(\mathrm{~m} \mu)$ & $\mathrm{D} 50(\mathrm{~m} \mu)$ & D90 $(\mathrm{m \mu})$ & D. MÉDIO $(m \mu)$ \\
\hline & $1 \mathrm{~h}$ & 4,4 & 25,66 & 49,2 & 26,57 \\
\hline & $2 \mathrm{~h}$ & 2,28 & 12,6 & 31,2 & 15,24 \\
\hline & $4 \mathrm{~h}$ & 1,54 & 7,88 & 20,03 & 9,61 \\
\hline \multirow{4}{*}{ CCA Ad. PG 6\% } & 30min & 11,15 & 40,91 & 75,31 & 42,59 \\
\hline & $1 \mathrm{~h}$ & 4,79 & 26,35 & 48,01 & 26,53 \\
\hline & $2 \mathrm{~h}$ & 2,26 & 12,72 & 31,15 & 15,26 \\
\hline & $4 \mathrm{~h}$ & 1,54 & 8,18 & 20,62 & 9,93 \\
\hline \multirow{4}{*}{ CCA Ad. PG 10\% } & $30 \mathrm{~min}$ & 10,17 & 40,55 & 77,53 & 42,81 \\
\hline & $1 \mathrm{~h}$ & 4,4 & 25,38 & 47,56 & 25,88 \\
\hline & $2 \mathrm{~h}$ & 2,41 & 13,38 & 33,39 & 16,2 \\
\hline & $4 \mathrm{~h}$ & 1,59 & 8,29 & 20,85 & 10,06 \\
\hline
\end{tabular}

Observa-se que os menores diâmetros médios foram obtidos em todas as CCA moídas por 4 horas, independente do uso de aditivo ou não. Em relação ao diâmetro da partícula, a CCA com diâmetro médio inferior a $17 \mu$ m pode ser utilizada para diversas aplicações, como por exemplo, na produção de concretos, mais especificamente como filler. Portanto, conforme os valores apresentados, todas as CCAs deste trabalho a partir de 2 horas de moagem se enquadram no diâmetro necessário para este uso. Mas, somente as amostras de CCA que foram moídas por 4h atingiram o diâmetro médio do cimento, que tem em torno de $12 \mu \mathrm{m}$, portanto podendo substituí-lo parcialmente [12]. Já Ragosta et al. [23] colocam, que de modo geral, para utiliza-

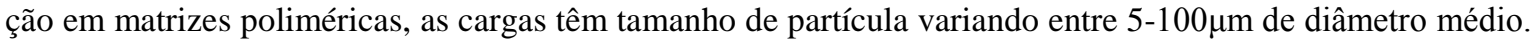
Dessa forma, pode-se inferir que as CCAs utilizadas neste trabalho se adequam para esta aplicação, com relação ao tamanho de partícula.

Analisando a Figura 8, ao se comparar a CCA com aditivo comercial com a moída sem aditivo, percebe-se que o diâmetro da partícula da CCA Ad. Com. começa a reduzir a partir de 1 hora. Este fato pode ser devido ao tipo de aditivo, por ser uma substância derivada de amina. Como estes compostos possuem uma faixa muito vasta de ponto de ebulição, não se pode indicar com certeza qual é o ponto de volatilização, mas sabe-se que existem grupos de aminas que volatilizam entre $17^{\circ} \mathrm{C}$ e $50^{\circ} \mathrm{C}$ [19]. Pode-se inferir que a moagem com o aditivo comercial, independente da concentração, por 30min, não atingiu a temperatura necessária para que este comece a dispersar as partículas. Observa-se que no tempo de moagem por 1 hora, a CCA Ad. PG obteve o diâmetro médio menor independente do teor de aditivo, indicando uma melhor eficiência comparada com o aditivo comercial, mas mesmo assim não atingiu o diâmetro adequado para tornar a CCA um coproduto para aplicação na construção civil na substituição do cimento, por exemplo.

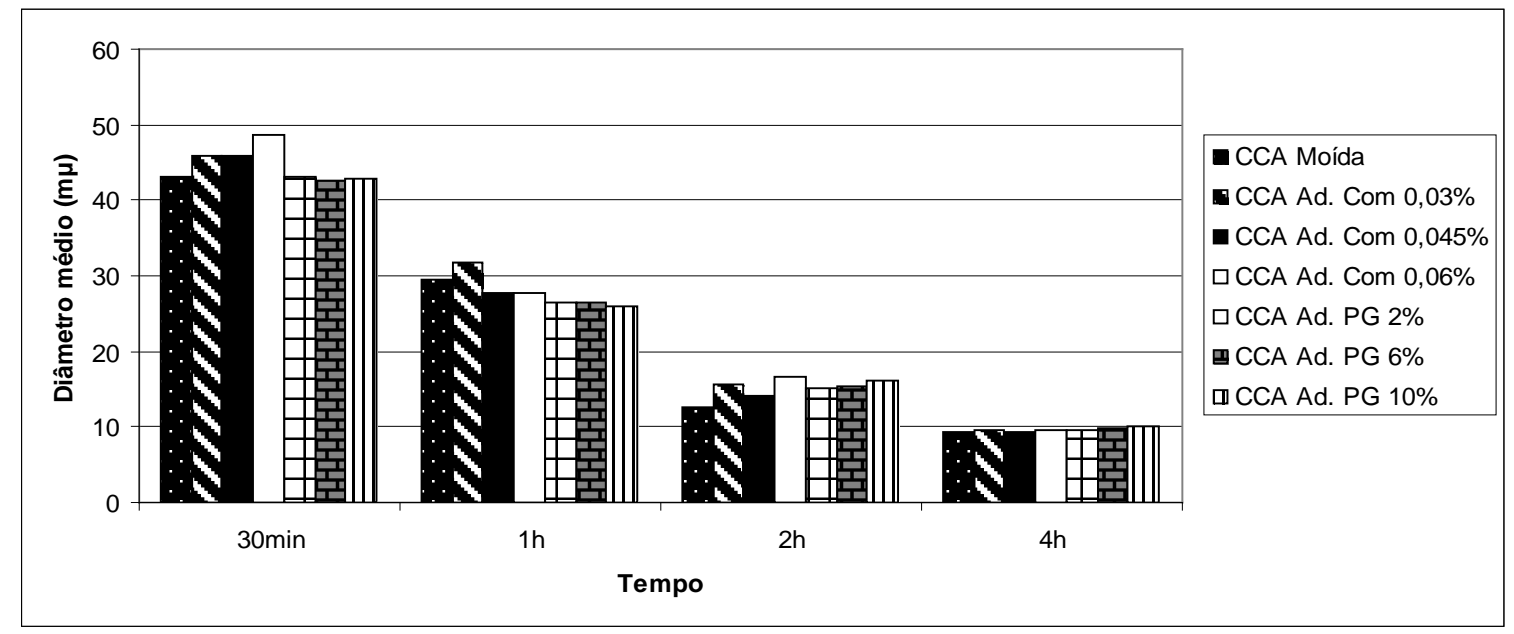

Figura 8: Comparação do diâmetro médio x tempo das CCA. 
Outra constatação é que o uso dos aditivos não influenciou no diâmetro médio das partículas, quando comparado com a CCA moída sem aditivo. Somente para as amostras contendo PG (para todos os teores) e nos tempos de 30 min e 1h, observou-se menores diâmetros médios do que na cinza moída sem aditivo.

\section{CONCLUSÕES}

Em relação à segregação granulométrica, pode-se comprovar que esta é uma etapa de essencial importância para utilização da CCA como coproduto, pois remove as impurezas oriundas do processo de combustão.

Baseados nos resultados dos ensaios é possível concluir que o aditivo comercial SikaGrind-200, utilizado para moagem de cimento, quando aplicado à CCA não foi efetivo e o mesmo acorreu para o resíduo pó de granalha. Portanto, estes aditivos, nas concentrações utilizadas no estudo, não influenciaram na redução do diâmetro das partículas. Outros estudos utilizando maiores concentrações destes aditivos são necessários, pois reduzir o tempo de moagem traz ganhos econômicos e ambientais, porque se minimiza o consumo de energia, e se valoriza o aproveitamento da CCA, como coproduto, evita-se que esta seja disposta em aterro industrial.

\section{AGRADECIMENTOS}

Os autores agradecem ao Banco Santander, à CAPES, à FAPERGS e aos itt Fuse e LCVMat Unisinos.

\section{BIBLIOGRAFIA}

[1] FOOD AND AGRICULTURE ORGANIZATION OF THE UNITED NATIONS STATISTICS - FAOSTAT, Food and Agricultural commodities production, [2014].

[2] FOOD AND AGRICULTURE ORGANIZATION OF THE UNITED NATIONS - FAO (Trade and Markets Division), Rice Market Monitor, Rome, 2014.

[3] FOLETTO, L. F., HOFFMANN, R., HOFFMANN, R.S., et al. “Aplicabilidade das cinzas da casca de arroz”, Química Nova, v. 28, n. 6, p. 1055-1060, 2005.

[4] MEHTA, P. K., MONTEIRO, P. J. M. Concreto: estrutura, propriedades e materiais, São Paulo, Pini, 1994.

[5] ARMESTO, L., BAHILL, A., VEIJONEN, K., et al. "Combustion Behavior of Rice Husk in a Bubbing Fluidised Bed”, Biomass and Bioenergy, v. 23, p. 171-179, 2002.

[6] MACHADO, M. M., ALFARO, E. F., FERRO, W. P., et al. Estudo da viabilidade da substituição do talco por cinza da casca de arroz como carga em Polipropileno, In: 9 Congresso Brasileiro de Polímeros, Campina Grande, 2007.

[7] CORDEIRO, L. N. P. Análise da variação do índice de amorfismo da cinza de casca de arroz sobre a atividade pozolânica, Dissertação de M.Sc.,Universidade Federal do Rio Grande do Sul, UFRGS, Porto Alegre, RS, 2009.

[8] NEHDI, M., DUQUETTE, J., EL DAMATTY, A. "Performance of rice husk ash produced using a new technology as mineral admixtures in concrete”, Cement and Concrete Research, v. 33, p. 1203-1210, 2003.

[9] ZAIN, M. F. M., ISLAM, M. N., MAHMUD, F., et al. "Production of rice husk ash for use in concrete as a supplementary cementitious material”, Construction and Building Materials, v. 25, n.2, p. 798-805. 2011.

[10] YIN, C., ROSENDAHL, L. A., KÆR, S. K. “Grate-firing of biomass for heat and power production”, Progress in Energy and Combustion Science, v. 34, p. 725-754, 2008.

[11] KIELING, A. G. Influência da Segregação no Desempenho de Cinzas de Casca de Arroz como Pozolanas e Material, Dissertação de M.Sc., UNISINOS, São Leopoldo, RS, 2009.

[12] POUEY, M. T. F. Beneficiamento da cinza de casca de arroz residual com vistas à produção de cimento composto e/ou pozolânico, Tese de D.Sc.,UFRGS, Porto Alegre, RS, 2006.

[13] LUZ, A. B., SAMPAIO, J. A., ALMEIDA, S. L. M. Tratamento de minérios, Rio de Janeiro, CETEM, 2004.

[14] WELLENKAMP, F. Moagens fina e ultrafina de minerais industriais: uma revisão. Rio de Janeiro, CETEM/MCT, 1999.

[15] ASSOCIAÇÃO BRASILEIRA DE FUNDIÇÃO. CEMP (Comissão de Estudos de Matérias Primas) nº 120: Materiais para Fundição - Determinação da Perda ao Fogo, São Paulo, ABIFA, 2003. 
[16] ASSOCIAÇÃO BRASILEIRA DE NORMAS TÉCNICAS. NBR NM 23: Cimento Portland e outros materiais em pó - Determinação da massa específica, Rio de Janeiro, ABNT, 2001.

[17] ASSOCIAÇÃO BRASILEIRA DE FUNDIÇÃO. CEMP (Comissão de Estudos de Matérias Primas) nº 081: Materiais para Fundição - Determinação da Distribuição Granulométrica, São Paulo, ABIFA, 2003.

[18] TASHIMA, M. M. Cinza de casca de arroz altamente reativa: método de produção, caracterização físico-química e comportamento em matrizes de cimento Portland, Tese de D.Sc., UNESP, São Paulo, SP 2006.

[19] RUSSEL, J. B. Química Geral. 2 ed. v. 2. São Paulo, Makron Books, 1994.

[20] SIKA. Produto SikaGrind-200. Ficha Técnica de Produto, 2005.

[21] COSTA, H. M., et al. "Cinética de vulcanização de composições de borracha natural com incorporação de cinza de casca de arroz”, Polímeros, São Carlos, v. 13, n. 2, p. 102-106, Jun. 2003.

[22] FERNANDES, I. J.. Desenvolvimento e caracterização de compósitos de cinza de casca de arroz em matriz epóxi. 2015. 168 f. Dissertação de M.Sc., UNISINOS, São Leopoldo, RS, 2015.

[23] RAGOSTA, G., ABBATE, M., MUSTO, P., et al., "Epoxy-silica particulate nanocomposites: Chemical interactions, reinforcement and fracture toughness”, Polymer, v. 46, p. 10506-10516, 2005. 